\title{
Study of Structure Making/Breaking Properties of Glucose, Fructose, Sucrose and Maltose in Aqueous KCl at Various Temperatures
}

\author{
K. H. KAPADNIS* and A. P. HIRAY \\ P.G. Department of Chemistry, \\ M.G.Vidyamandir's L.V.H. College, Nashik-422003, Maharshtra, India \\ khkapadnis@yahoo.co.in
}

Received 22 October 2012 / Accepted 12 November 2012

\begin{abstract}
The volumetric and viscometric studies of glucose, fructose, sucrose and maltose have been determined in $0.05 \mathrm{M}$ and $0.5 \mathrm{M} \mathrm{KCl}$ solutions at 298.15, 303.15, 308.15 and $313.15 \mathrm{~K}$. The apparent molar volume $\left(\phi_{\mathrm{v}}\right)$ values vary linearly with square root of concentration of $\mathrm{KCl}$ solution. The limiting apparent molar volume $\left(\phi_{\mathrm{v}}^{0}\right)$ has been interpreted in terms of solute-solvent interaction. The $\phi_{\mathrm{v}}^{0}$ values vary with temperature and can be represented in the power series of structure making and breaking capacity of electrolyte is inferred from the sign of $\mathrm{dB} / \mathrm{dT}$ values. The apparent molar expansibility has also been determined. Glucose, fructose, sucrose and maltose have been found to be structure maker and breaker in aqueous $\mathrm{KCl}$ from molar volume as well as viscosity studies.
\end{abstract}

Keywords: Moulik, Glucose, Fructose, Massion, Jone-Dole

\section{Introduction}

The study of apparent molar volume of electrolyte at infinite dilutions, B parameter of the Jone-Dole and $\mathrm{M}$ and $\mathrm{K}$ parameter of Moulik equation for viscosity and their dependence on temperature can furnish useful information on the nature of solute- solvent interactions. The behavior of electrolyte in aqueous carbohydrate solutions recently has been a subject of interest $^{1-3}$. Sacharide molecules having several hydroxyl groups interact with metal ions to produce a variety of metal-sacharide complexes. These complexes are weak, but the interactions are specific ${ }^{4-5}$. The range of applications of osmotic treatment is wide. Fruits, vegetables, meat and fish can be osmotically treated preceding conventional processing ${ }^{6-7}$. Binary and ternary aqueous solutions of sugars, inorganic salts; alcohols and polyols can be used as osmotic agents. The use of mixed blend makes it possible to take benefit from the respective advantages of each solute. Therefore the understanding of osmotic treatment needs to take in to account the physical properties of the aqueous solutions. Only few studies are available on densities and viscosities of concentrated water + sugar $+\mathrm{NaCl}^{8-9}$. The objective of this work was to measure density and viscosity of the ternary system water + 
sugar $+\mathrm{KCl}$ and attempt had been made to correlate solute-solvent interaction, structure maker/breaker properties and various type of other molecular interactions in the temperature range $298.15 \mathrm{~K}$ to $313.15 \mathrm{~K}$.

\section{Experimental}

Water used for solutions was triple distilled had specific conductance $5 \times 10^{-6}$ mhos.cm ${ }^{-1}$. Glucose, fructose, sucrose, maltose and $\mathrm{KCl}$ (Analar R) with purity more than $99.9 \%$ were vacuum dried and used as such. The solution of different molarities of these sugars $(0.11 \mathrm{M}$ $0.25 \mathrm{M})$ were prepared by dissolving accurately weighed amount of sugars in $(0.05 \mathrm{M}$ and $0.5 \mathrm{M}$ ) aqueous solutions of $\mathrm{KCl}$. The density and viscosity measurements ${ }^{10}$ were carried out by Bicapillary pycnometer and Ublhode viscometer respectively at 298.15, 303.15, 308.15 and $313.15 \mathrm{~K}$ in a glass wall thermostat water bath, temperature were recorded with the help of thermometer having accuracy of $\pm 0.01{ }^{0} \mathrm{C}$.

\section{Results and Discussion}

The apparent molar volume of glucose, fructose, sucrose and maltose in aqueous $\mathrm{KCl}$ solutions has been calculated from density data by using the following equation ${ }^{11}$

$$
\phi_{\mathrm{v}}=\mathrm{M}_{2} / \mathrm{d}_{0}-1000\left(\mathrm{~d}-\mathrm{d}_{0}\right) / \mathrm{md}_{0}
$$

Where $d_{0}$ is the density of solvent, $d$ is density of solution and $M_{2}$ the molecular weight of the salt and $\mathrm{m}$ is a molar concentration of solute. Errors in $\phi_{\mathrm{v}}$ were calculated from the following equation ${ }^{12}$.

$$
\Delta \phi_{\mathrm{v}}=\left(2 \Delta \mathrm{d} / \mathrm{d}^{2}\right)\left(1000 / \mathrm{m}+\mathrm{M}_{2}\right)
$$

Equation (2) assumes error to be associated with the density of the solution (d) and solvent $\left(d_{0}\right)$. Moreover, errors associated with determination of solution $\left(d_{0}\right)$ concentration are not the limiting factor while calculating the apparent molar volume. The error in apparent molar volume as derived from equation (2) was estimated from $\pm 0.162 \mathrm{~cm}^{3} \mathrm{~mol}^{-1}$ at $0.05 \mathrm{M} \mathrm{KCl}$ concentration to $\pm 0.399 \mathrm{~cm}^{3} \mathrm{~mol}^{-1}$ at $0.5 \mathrm{M} \mathrm{KCl}$ concentration. The densities of various solutions of glucose, fructose, sucrose and maltose in aqueous $\mathrm{KCl}$ obey Roots equation and justify the use of Massion equation (3) for the estimation of the apparent molar volume.

$$
\phi_{\mathrm{v}}=\phi_{\mathrm{v}}^{0}+\mathrm{S}_{\mathrm{v}} \mathrm{C}^{1 / 2}
$$

Where $\phi_{\mathrm{v}}$ and $\mathrm{S}_{\mathrm{v}}$ are calculated from the intercept and slope from the extrapolation of the plots of $\phi_{\mathrm{v}}$ versus $\mathrm{C}^{1 / 2}$. The values of limiting molar volume and slope $\mathrm{S}_{\mathrm{v}}$ are recorded in Table 1 .

Table 1. The limiting apparent molar volume $\phi_{\mathrm{v}}^{0}$ and $S_{\mathrm{v}}$ for (a) glucose (b) fructose (c) sucrose and (d) maltose in aqueous $\mathrm{KCl}$ at different temperature.

\begin{tabular}{cccc}
\multicolumn{4}{c}{ (a) Glucose } \\
\hline $\begin{array}{c}\text { Concentration of } \\
\text { KCl, mol.L }{ }^{-1}\end{array}$ & $\begin{array}{c}\text { Temp., } \\
\mathrm{K}\end{array}$ & $\begin{array}{c}\phi^{0}{ }_{\mathrm{v}}, \\
\mathrm{cm}^{3} \mathrm{~mol}^{-1}\end{array}$ & $\begin{array}{c}\mathrm{S}_{\mathrm{v}}, \\
\mathrm{cm}^{3} . \mathrm{L}^{1 / 2} \mathrm{Mol}^{3 / 2}\end{array}$ \\
\hline 0.05 & 298.15 & $116.1(112.1)$ & $35.1(34.0)$ \\
& 303.15 & $116.7(112.5)$ & $36.1(36.1)$ \\
& 308.15 & $117.1(113.1)$ & $38.4(37.4)$ \\
0.5 & 313.15 & $117.6(113.6)$ & $39.3(38.1)$ \\
& 298.15 & 118.2 & 37.2 \\
& 303.15 & 118.8 & 38.2 \\
& 308.15 & 119.4 & 39.4 \\
& 313.15 & 119.9 & 40.5 \\
\hline
\end{tabular}


(b) Fructose:

\begin{tabular}{cccc}
\hline $\begin{array}{c}\text { Concentration of } \\
\text { KCl, mol.L } L^{-1}\end{array}$ & $\begin{array}{c}\text { Temp., } \\
\mathrm{K}\end{array}$ & $\begin{array}{c}\phi^{0}{ }_{\mathrm{v}}, \\
\mathrm{cm}^{3} \mathrm{~mol}^{-1}\end{array}$ & $\begin{array}{c}\mathrm{S}_{\mathrm{v}}, \\
\mathrm{cm}^{3} . \mathrm{L}^{1 / 2} \mathrm{Mol}^{3 / 2}\end{array}$ \\
\hline 0.05 & 298.15 & $112.2(110.6)$ & $29.2(28.0)$ \\
& 303.15 & $112.7(111.1)$ & $31.2(30.1)$ \\
& 308.15 & $113.0(111.6)$ & $33.7(31.5)$ \\
0.5 & 313.15 & $113.4(112.0)$ & $34.4(32.2)$ \\
& 298.15 & 114.4 & 31.4 \\
& 303.15 & 114.8 & 33.4 \\
& 308.15 & 115.3 & 35.8 \\
\hline
\end{tabular}

(c) Sucrose

\begin{tabular}{cccc}
\hline $\begin{array}{c}\text { Concentration of } \\
\text { KCl, mol. } \mathrm{L}^{-1}\end{array}$ & $\begin{array}{c}\text { Temp., } \\
\mathrm{K}\end{array}$ & $\begin{array}{c}\phi^{0} \mathrm{v}, \\
\mathrm{cm}^{3} \mathrm{~mol}^{-1}\end{array}$ & $\begin{array}{c}\mathrm{S}_{\mathrm{v}}, \\
\mathrm{cm}^{3} . \mathrm{L}^{1 / 2} \mathrm{Mol}^{3 / 2}\end{array}$ \\
\hline 0.05 & 298.15 & $216.9(215.4)$ & $27.5(27.5)$ \\
& 303.15 & $217.8(215.5)$ & $28.7(28.4)$ \\
& 308.15 & $218.8(215.5)$ & $29.5(29.3)$ \\
0.5 & 313.15 & $219.6(215.6)$ & $30.2(30.1)$ \\
& 298.15 & 218.2 & 29.9 \\
& 303.15 & 219.1 & 30.8 \\
& 308.15 & 220.5 & 31.5 \\
& 313.15 & 221.5 & 32.6 \\
\hline
\end{tabular}

(d) Maltose:

\begin{tabular}{cccc}
\hline $\begin{array}{c}\text { Concentration of } \\
\text { KCl, mol.L }\end{array}$ & $\begin{array}{c}\text { Temp., } \\
\mathrm{K}\end{array}$ & $\begin{array}{c}\phi_{\mathrm{v}}^{0}, \\
\mathrm{~cm}^{3} \mathrm{~mol}^{-1}\end{array}$ & $\begin{array}{c}\mathrm{S}_{\mathrm{v}}, \\
\mathrm{cm}^{3} . \mathrm{L}^{1 / 2} \mathrm{Mol}^{3 / 2}\end{array}$ \\
\hline 0.05 & 298.15 & $222.3(217.3)$ & $33.5(31.6)$ \\
& 303.15 & $222.4(217.3)$ & $34.3(32.4)$ \\
& 308.15 & $222.5(217.4)$ & $35.2(33.3)$ \\
0.5 & 313.15 & $222.6(217.5)$ & $36.1(34.2$ \\
& 298.15 & 228.5 & 35.8 \\
& 303.15 & 228.6 & 36.7 \\
& 308.15 & 228.7 & 37.5 \\
& 313.15 & 228.8 & 38.5 \\
\hline
\end{tabular}

The intercept $S_{v}$ in Massion equation may be attributed to be as a measure of ion-ion or solute-solute intercations ${ }^{13-15}$, it is obvious from the sign of $S_{v}$ that solute-solute interaction are present and increases with increase in concentration of $\mathrm{KCl}$ in glucose, fructose, sucrose and maltose. The attractions are increasing with increase in temperature for sugars in aqueous $\mathrm{KCl}$ solutions. The slope $\mathrm{S}_{\mathrm{v}}$ is positive for glucose, fructose, sucrose and maltose solutions in aqueous $\mathrm{KCl}$ solutions. This positive $\mathrm{S}_{\mathrm{v}}$ values from Debye-Huckel theory ${ }^{11}$ showed that sugars will be considerably associated in presence of ions.

$\phi_{\mathrm{v}}^{0}$ is a measure of solute- solvent interactions. The $\phi_{\mathrm{v}}^{0}$ values of sugar investigated in aqueous $\mathrm{KCl}$ solutions and in water are large and positive. This indicates the presence of strong solute- solvent interactions. It is further observed that $\phi_{\mathrm{v}}^{0}$ in all systems increases slightly with increase in temperature suggesting loosening of solute- solvent interactions at elevated temperatures. 
It is interesting to note further that $\phi_{\mathrm{v}}^{0}$ values of sugar solutions in water are further influenced by addition of $\mathrm{KCl}$ in water. $\phi_{\mathrm{v}}^{0}$ Values of sugar solutions in presence of added $\mathrm{KCl}$ are higher than those for sugars in pure water (Given in parenthesis in Table 1). This indicates that the structure of water modified by sugars get enhanced in the presence of ions of $\mathrm{KCl}$. The limiting excess molar volumes of sugars for different compositions of $\mathrm{KCl}$ have been estimated from equation (4)

$$
\Delta \phi_{\mathrm{v}}^{0}(\text { excess })=\phi_{\mathrm{v}}^{0}(\text { sugar in } \mathrm{KCl})-\phi_{\mathrm{v}}^{0}(\text { Sugar in water })
$$

$\Delta \phi_{\mathrm{v}}^{0}$ (excess) increases with increase in concentration of $\mathrm{KCl}$ and almost remains constant with increase in temperature (Table 2).

Table 2. Limiting excess molar volumes of sugars in $\mathrm{KCl}$ at different temperatures

\begin{tabular}{cccccc}
\hline Composition & Temp. & \multicolumn{4}{c}{$\Delta \phi_{\mathrm{v}}^{0}$} \\
\cline { 3 - 6 } of KCl, $\mathrm{M}$ & $\mathrm{K}$ & Glucose & Fructose & Sucrose & Maltose \\
\hline 0.05 & 298.15 & 4.0 & 2.2 & 5.6 & 5.0 \\
& 303.15 & 4.2 & 1.6 & 6.5 & 5.1 \\
& 308.15 & 4.0 & 1.4 & 7.4 & 5.1 \\
0.5 & 313.15 & 4.0 & 1.3 & 8.2 & 5.1 \\
& 298.15 & 6.1 & 3.8 & 6.6 & 10.0 \\
& 303.15 & 6.3 & 3.7 & 7.8 & 10.7 \\
& 308.15 & 6.3 & 3.7 & 9.3 & 11.3 \\
& 313.15 & 6.3 & 4.0 & 10.0 & 11.3 \\
\hline
\end{tabular}

Viscosity data has been analyzed on the basis of John-Dole and modified John-Dole equation $^{16-17}$.

$$
\begin{aligned}
& \eta_{\mathrm{s}} / \eta_{0}=1+\text { A C } 1 / 2+\mathrm{BC} \\
& \eta_{\mathrm{s}} / \eta_{0}=1+\text { BC --- }(0.125-0.3 \mathrm{~m})
\end{aligned}
$$

Where $\eta_{s}$ and $\eta_{0}$ are viscosities of solutions and solvent respectively, A and B are constants. The values of $\mathrm{A}$ and $\mathrm{B}$ have been determined from intercept and slope of linear plots of $\eta_{s} / \eta_{0}-1 /$ C $1 / 2$ versus $C 1 / 2$ for equation (5) and $B^{*}$ as a slope of modified John-Dole equation for the plot of $\eta_{\mathrm{s}} / \eta_{0}$ versus $C$. The values are listed in Table 3.

Table 3. Values of John-Dole and modified John-Dole parameter for (a) glucose (b) fructose (c) sucrose and (d) maltose solutions in aqueous $\mathrm{KCl}$ at different temperatures

(a) Glucose

\begin{tabular}{ccccc}
\hline \multirow{2}{*}{$\begin{array}{c}\text { Concentration } \\
\text { of KCl, mol.L }\end{array}$} & Temp., & \multicolumn{2}{c}{ Jone Dole Parameters } & Modified Jone Dole \\
\cline { 3 - 4 } & $\mathrm{K}$ & $\mathrm{A}$ & $\mathrm{B}$ & Parameters B $^{*}$ \\
\hline 0.05 & 298.15 & $0.068(-0.008)$ & $0.448(0.559)$ & $0.400(0.534)$ \\
& 303.15 & $0.015(0.003)$ & $0.368(0.487)$ & $0.389(0.506)$ \\
& 308.15 & $0.065(0.01)$ & $0.340(0.478)$ & $0.318(0.486)$ \\
0.5 & 313.15 & $0.003(-0.017)$ & $0.322(0.408)$ & $0.309(0.466)$ \\
& 298.15 & 0.041 & 0.368 & 0.385 \\
& 303.15 & 0.009 & 0.344 & 0.372 \\
& 308.15 & 0.028 & 0.326 & 0.353 \\
& 313.15 & 0.038 & 0.300 & 0.338 \\
\hline
\end{tabular}


(b) Fructose

\begin{tabular}{cclll}
\hline Concentration & Temp., & \multicolumn{2}{c}{ Jone Dole Parameters } & \multicolumn{1}{c}{$\begin{array}{c}\text { Modified Jone Dole } \\
\text { of KCl, mol.L }\end{array}$} \\
\cline { 3 - 4 } & $\mathrm{K}$ & \multicolumn{1}{c}{$\mathrm{A}$} & \multicolumn{1}{c}{$\mathrm{B}$} & \multicolumn{1}{c}{ Parameters B $^{*}$} \\
\hline 0.05 & 298.15 & $0.007(0.064)$ & $0.405(0.565)$ & $0.410(0.603)$ \\
& 303.15 & $0.003(0.004)$ & $0.395(0.53)$ & $0.395(0.545)$ \\
& 308.15 & $-0.014(0.026)$ & $0.380(0.451)$ & $0.382(0.494)$ \\
0.5 & 313.15 & $0.024(0.007)$ & $0.345(0.417)$ & $0.370(0.432)$ \\
& 298.15 & 0.24 & 0.469 & 0.468 \\
& 303.15 & -0.01 & 0.455 & 0.441 \\
& 308.15 & -0.02 & 0.450 & 0.431 \\
& 313.15 & -0.02 & 0.434 & 0.412 \\
\hline
\end{tabular}

(c) Sucrose

\begin{tabular}{ccccc}
\hline $\begin{array}{c}\text { Concentration } \\
\text { of KCl, mol.L }\end{array}$ & Temp., & \multicolumn{2}{c}{ Jone Dole Parameters } & $\begin{array}{c}\text { Modified Jone Dole } \\
\text { Parameters B }\end{array}$ \\
\cline { 3 - 4 } & $\mathrm{K}$ & $\mathrm{A}$ & $\mathrm{B}$ & \\
\hline 0.05 & 298.15 & $0.194(-0.02)$ & $0.576(1.025)$ & $0.801(0.982)$ \\
& 303.15 & $0.153(-0.005)$ & $0.541(0.975)$ & $0.718(0.954)$ \\
& 308.15 & $0.192(-0.004)$ & $0.396(0.947)$ & $0.618(0.927)$ \\
0.5 & 313.15 & $0.204(-0.012)$ & $0.291(0.931)$ & $0.527(0.901)$ \\
& 298.15 & 0.099 & 0.599 & 0.706 \\
& 303.15 & 0.103 & 0.510 & 0.623 \\
& 308.15 & 0.141 & 0.366 & 0.524 \\
& 313.15 & 0.163 & 0.254 & 0.438 \\
\hline
\end{tabular}

(d) Maltose

\begin{tabular}{|c|c|c|c|c|}
\hline \multirow{2}{*}{$\begin{array}{l}\text { Concentration } \\
\text { of } \mathrm{KCl}, \mathrm{mol} . \mathrm{L}^{-1}\end{array}$} & \multirow{2}{*}{$\begin{array}{c}\text { Temp. } \\
\text { K }\end{array}$} & \multicolumn{2}{|c|}{ Jone Dole Parameters } & \multirow{2}{*}{$\begin{array}{l}\text { Modified Jone Dole } \\
\text { Parameters B* }\end{array}$} \\
\hline & & A & B & \\
\hline \multirow[t]{4}{*}{0.05} & 298.15 & $-0.017(0.002)$ & $1.027(0.971)$ & $1.00(0.992)$ \\
\hline & 303.15 & $-0.058(0.054)$ & $1.006(0.832)$ & $0.933(0.927)$ \\
\hline & 308.15 & $-0.017(0.041)$ & $0.889(0.786)$ & $0.863(0.861)$ \\
\hline & 313.15 & $-0.016(0.028)$ & $0.882(0.742)$ & $0.789(0.796)$ \\
\hline \multirow[t]{4}{*}{0.5} & 298.15 & 0.006 & 0.919 & 0.923 \\
\hline & 303.15 & 0.007 & 0.887 & 0.882 \\
\hline & 308.15 & 0.008 & 0.859 & 0.866 \\
\hline & 313.15 & -0.014 & 0.857 & 0.839 \\
\hline
\end{tabular}

Parameter A of Jone-Dole equation represents the contribution from solute-solute interactions ${ }^{18}$. The positive and negative values are small in magnitude due to weak solutesolute interactions. The parameter $\mathrm{B}$ and $\mathrm{B}^{*}$ represents the structure-making/breaking capacity of an electrolyte in a solution also contain a contribution from structural effects and is responsible for solute- solvent interaction in a solvent ${ }^{19}$. It has been emphasized by a number of workers that $\mathrm{dB} / \mathrm{dT}$ is more important criterion ${ }^{20}$ for determining solute -solvent interaction, as positive $\mathrm{B} / \mathrm{B}^{*}$ coefficient obtained for glucose, fructose, sucrose and maltose in aqueous $\mathrm{KCl}$ solution can be interpreted as merely due to large size of ion. The value shown in parenthesis is that for respective parameters measured in water. Viscosity study of a number of salts has shown that structure makers will have negative $\mathrm{dB} / \mathrm{dT}$. 


\section{Conclusion}

The positive value of excess molar volume of sugars in aqueous $\mathrm{KCl}$ solutions may be attributed to the increase in the solute-solvent interactions at infinite dilutions. " $A$ " Parameter of Jone-Dole equation represents the contribution from solute-solute interactions ${ }^{18}$. The positive and negative values are small in magnitude due to weak solutesolute interactions.

The temperature effect on glucose, fructose, sucrose and maltose in 0.05 and $0.5 \mathrm{M}$ aqueous $\mathrm{KCl}$ solution shows a negative sign of $\mathrm{dB} / \mathrm{dT}$ showing thereby that sugars investigated behaves as a structure maker.

\section{References}

1. $\quad$ Bonner O D, J Sol Chem., 1982, 11, 315-324.

2. $\quad$ Dash U N, Dash B B, Biswal U K and Panda T, J Electrochim Soc India, 1985, 34, 215.

3. Movel J P, Chermel L and Deroriers N M, J Chem Soc Faraday Trans 1, 1998, 84, 2567.

4. $\quad$ Ronger P, Desrosier N M and Morel J P, J Chem Soc Faraday Trans., 1995, 91, 2771.

5. $\quad$ Rao C P and Das T M, Indian J Chem., 2003, 42A, 227-239.

6. Papanatasiou G E and Ziogas J, Chem Eng Data, 1992, 37, 167-172.

7. $\quad$ Keel and Whalley G S, J Chem Phys., 1975, 62, 3496.

8. $\quad$ Ruostesuo P and Mattila T, J Chem Eng Data, 1987, 32, 241-243.

9. Hales J L and Ellender J H, J Chem Thermodyn., 1976, 8, 1177.

10. Nikam P S and Nikumbh A B, J Chem Eng Data, 2002, 47, 400.

11. Redlich O and Meyer D M, Chem Rev., 1964, 64, 221.

12. Shashikant and Kumar S and Thkur M, Scholar Research Library, Archives Appl Sci Res., 2012, 4(3), 1462.

13. Deosarkar S D and Narwade M L, J Chem Bio Phy Sci., 2012, 2(3), 1200.

14. Nikam P S, Ansari H R and Hasan M, J Indian Chem Soc., 1999, 76, 344.

15. Millero F J, J Chem Eng Data, 1973, 18, 407.

16. Jones G and Dole M, J Am Chem Soc., 1929, 51, 2950-2964.

17. Breslau B R and Miller I F, J Phy Chem., 1970, 74, 1056.

18. Falkenhegan H and Dole M, Phy Z., 1929, 30, 611-616.

19. Nightingale E R, in Chemical physics of ionic solutions edited by Conway B E and Barradas, Wiley, New York, 1966, 93.

20. Sharma T S and Ahluwalia J C, Rev Chem Soc., 1973, 2, 2. 